\title{
Induced Demand: A Microscopic Perspective
}

\author{
Pavithra Parthasarathi, David M. Levinson and Ramachandra Karamalaputi \\ [Paper first received, March 2002; in final form, October 2002]
}

Summary. This paper analyses the induced demand hypothesis using a disaggregate approach at the link level. A panel data-set of Minneapolis-Saint Paul highway network for the years 1980-98 is constructed. A model that predicts the traffic flow on the link in terms of vehicle kilometres travelled (VKT) based on the flow and capacity conditions existing on the link in the previous years is specified and estimated. The flow and capacity conditions existing on the identified neighbouring parallel links are also taken into account. Socio-demographic characteristics like population of the Minor Civil Division (MCD) to which the link belongs and the surrounding MCDs are also considered. The results indicate that capacity enhancements in the previous years, given by lane additions, have a positive and significant effect on the VKT of the link, confirming the induced demand hypothesis. The elasticities are lower than reported in previous research, indicating the importance of separating new construction from the expansion of existing links.

\section{Introduction}

Transport forecasts often assume limited or no response of demand to changes in supply. This supposition has been refuted by others, economists in particular. Anthony Downs (1992), for instance, famously postulated the idea of 'triple convergence' (also referred to as the 'Iron Law of Congestion') which says that when capacity is added, drivers switch routes, times and modes to take advantage of the more desirable capacity. Moreover, in the longer term, people move and change jobs, while activities relocate to absorb new capacity. Nevertheless, considerable controversy has existed over the existence and importance of the response of demand to supply, also referred to as induced or latent demand. According to the induced demand hypothesis as stated by Fulton et al. (2000), additions to highway capacity cause travel to increase. The presence of this relationship also raises the question of whether capacity expansions provide net costs or benefits to society, as additional travel generates negative externalities.

Research on the induced demand hypothesis to date has mostly been carried out at the aggregate level, considering state, metropolitan or county-level traffic and capacity data. However, disaggregation of travel data is essential to understand where induced 
demand effects are the greatest (Noland, 1999). This study analyses the induced demand hypothesis at the disaggregate level.

The highway network for the metropolitan area of the 'Twin Cities' of Minneapolis and Saint Paul, Minnesota, is analysed at the link level using a network from the regional planning agency and linking it with a traffic counts database and data from the capital improvement programme. This microscopic focus allows the analysis of the induced demand hypothesis in greater detail. In addition to the flow and capacity variables, factors like the population of Minor Civil Division (MCD) and adjacent MCDs, and flow and capacity on parallel links are also taken as variables in the analysis.

The study focuses on network evolution while controlling for network interactions. This in essence means looking at how the network has grown over time. The Twin Cities network for the year 1995 from the metropolitan planning organisation is taken as the base case and the network is built (or deconstructed) for the years from 1978 to 1998 using the investment data that were obtained from the capital improvement programmes. The focus is on the effects of widening a road, in contrast with some earlier studies that emphasised new construction, or conflated the effects of new links with widened links. It is expected that the effects of the two are different in magnitude (though not direction), as link expansions serve existing populations more, while new construction tends to support future residents.

The rest of this paper is organised as follows. The next section provides a brief background and review of the literature on this topic. A description of the data-sets used for the analysis and the procedures required to format the data-set for use in this study are then described. This is followed by an explanation of the basic model used in this study and its functional forms. A brief introduction of selectivity bias in the models and its correction procedure is given in the next section. A description follows of the hypothesis formulated, the analyses done and the results obtained. Finally, the paper concludes with the key findings from the study.

\section{Background}

Transport planners and economists have acknowledged the presence of induced travel to changes in road capacity since the 1930s when benefit-cost analyses were first applied to road projects. Recently, however, there has been an increasing interest in the relationship and size of this travel response to changes in highway capacity. A great deal of attention has been placed on the potential of new construction to increase traffic (Kiefer and Mehndiratta, 1998). Strathman et al. (2000) feel that this attention has been caused by concerns about the relationship between highway construction, air quality and urban development patterns. Recently there has been increased emphasis on strategies that are demand-oriented or which better manage existing infrastructure. Urban road construction has suffered from diminished finances and concerns of adverse environmental effects. Studies have shown that there exists an indirect causal relationship between capacity increase and travel patterns, which induces growth in vehicle travel (Strathman et al., 2000).

Noland (1999) argued that increasing the capacity of a highway corridor attracts increased vehicle traffic. The basic theory of induced demand can be explained using the economic theory of supply and demand. From an economic perspective, the demand for travel is influenced by its cost. The cost of travel consists of the fixed capital costs of a vehicle inclusive of fuel and maintenance costs and the variable travel time costs. A highway capacity increase would reduce travel time and thus increase overall demand.

Figure 1 illustrates the induced travel hypothesis. $S_{1}$ represents the supply before the capacity expansion took place and $S_{2}$ represents the supply after the capacity expansion. $S_{2}$ is shifted downward with respect to $S_{1}$, indicating that the same demand is met at a lower cost than before the capacity expansion. The increase in travel or induced travel 


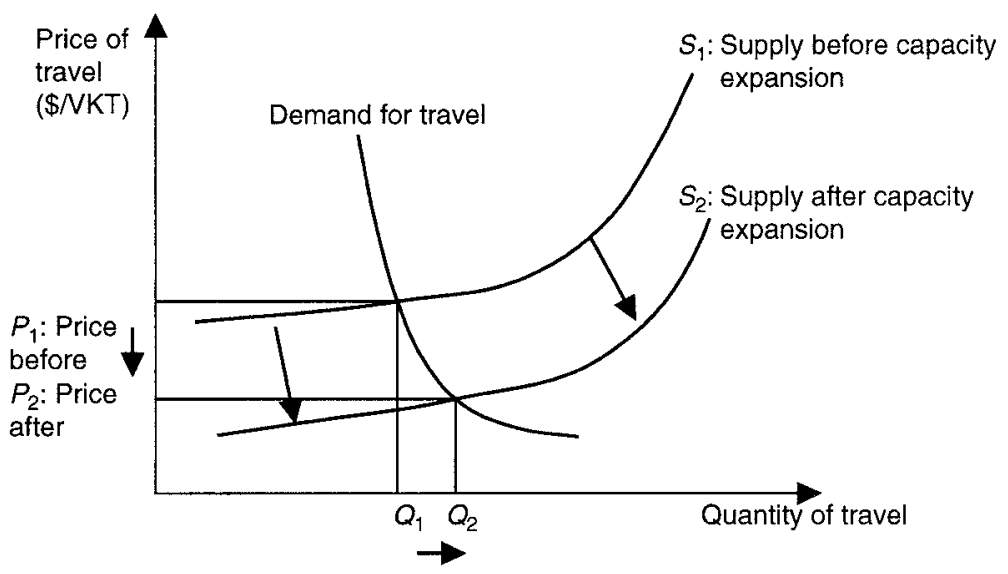

Figure 1. The induced travel hypothesis. Source: Noland (1999).

in terms of vehicle kilometres travelled (VKT) is indicated by $Q_{1}-Q_{2}$. The figure shows that the change in supply reduces the cost of travel and this in turn increases the amount of travel.

Noland (1999) also concluded that the induced demand hypothesis should not be rejected. This aggregate study used a cross-section of data from the 50 US states between 1984 and 1996. The results showed a significant relationship between capacity and distance travelled. Although there were other factors like population growth that contributed to increased distance travelled, increases in capacity accounted for nearly one quarter of this growth.

Fulton et al. (2000) looked at the induced demand hypothesis in the US Mid-Atlantic region using county-level data from Maryland, Virginia, North Carolina and Washington, DC. The Granger causality test that was conducted in this study showed that changes in travel were preceded by changes in lane kilometres.

Pfleiderer and Dieterich (1995) have argued about the presence of induced demand on the basis of the law of constant travel time budget. The question of travel time budgets is still unresolved, although evidence for a commute time budget is strong (Levinson and Kumar, 1994a; Barnes and Davis, 2001). A budget would suggest that, as capacity became available, link travel times would drop and much of the faster speeds would be absorbed in longer trips (and thus more VKT). Thus the speeds would still be better after the link expansion than before it, but not as much as a naïve model might suggest. Levinson and Kanchi (in press) developed a model to study the change in time use using the 1990 and 1995 NPTS data. The study identified how travel time and activity durations change with capacity. The study concluded that increases in highway capacity cause small but significant changes in individual daily travel behaviour and activity patterns.

Hansen and Huang (1997) estimated the relationship between state highway capacity and travel using panel data between 1973 and 1990 for the state of California. The authors conclude that increasing road capacity does not greatly reduce congestion in the long run.

Aside from added capacity, other factors that contribute to increased travel include growth in population, decreasing household sizes, saturation of vehicle availability phenomenon and the effect of dispersion of residences and work (Kiefer and Mehndiratta, 1998). These factors play a role in determining demand and increasing growth in urban travel independent of the supply.

Mokhtarian et al. (2001) test the existence of induced demand using a matched- pair approach. Eighteen California Highway segments were considered and these segments 
Table 1. Tabulation of elasticity estimates obtained by different studies

\begin{tabular}{|c|c|}
\hline Study & Elasticity \\
\hline Dowling and Colman (1995) & $\begin{array}{l}0.3-0.5 \text { per cent increase in trip generation due to congestion relieving } \\
\text { projects }\end{array}$ \\
\hline Fulton et al. (2000) & $\begin{array}{l}0.2-0.6 \text { per cent increase in VKT due to } 1 \text { per cent increase in lane } \\
\text { kilometres }\end{array}$ \\
\hline Hansen and Huang (1997) & $\begin{array}{l}0.6-0.7 \text { per cent increase in VKT due to } 1 \text { per cent increase in lane } \\
\text { kilometres (county level) } \\
0.9 \text { per cent increase in VKT due to } 1 \text { per cent increase in lane } \\
\text { kilometres (metropolitan level) }\end{array}$ \\
\hline Noland (1999) & $\begin{array}{l}0.2-0.5 \text { per cent increase in VKT due to } 1 \text { per cent increase in lane } \\
\text { kilometres (short-run estimates) } \\
0.7-1.0 \text { per cent increase in VKT due to } 1 \text { per cent increase in lane } \\
\text { kilometres (long-run estimates) }\end{array}$ \\
\hline Strathman et al. (2000) & $\begin{array}{l}0.29 \text { per cent direct effect for } 1 \text { per cent increase in road capacity } \\
0.033 \text { per cent indirect effect for } 10 \text { per cent increase in road capacity }\end{array}$ \\
\hline
\end{tabular}

were paired with control segments such that improved segments were paired with unimproved ones. The study concluded that there was no difference in the growth rates between the improved and unimproved segments. The authors believe, however, that the induced traffic effect due to capacity changes on existing facilities can be very small and hence its detection in such a study might not be possible without a large sample size.

From the studies, it seems difficult to reject the induced demand hypothesis. It is seen that increasing capacity reduces the cost of travel and results in greater travel and overall mobility. However, the Fulton et al. (2000) study indicates that the downside of increasing capacity is that the benefits from congestion reduction would be lost over time due to increased travel. A summary of the elasticity estimates obtained in the various studies is shown in Table 1.

\section{Data}

Four data-sets are used in the analysis. Network data for the year 1995 come from the Metropolitan Council for the Twin Cities, the region's metropolitan planning organisation. The data contain information on the highway network given by links, which are defined by the start and end node respectively. In addition, the data contain information on the length of the link, the number of lanes on the link, capacity and modelled traffic flows on the link. Each link has a coded road type and location. A summary of the 1995 highway network data is given in Table 2 .

Traffic counts data in the form of annual average daily traffic (AADT) are from the Minnesota Department of Transport (MnDOT). The AADT database contains the traffic volume for each roadway segment from 1978 to 1998 . The AADT represents an estimate of the daily volume of all motorised vehicles for the segments, the segments being defined by MnDOT (Office of Transport Data and Analysis, MnDOT). Table 3 summarises the change in vehicle kilometres travelled (AADT multiplied by link length) from 1980 to 1998. Figure 2 shows the change in lane km from 1980 to 1998.

Population estimates for the Minor Civil Divisions (MCDs) in the Twin Cities area from 1980 to 2000 are from the State Demographic Center at Minnesota Planning

Investment data are obtained from two sources. The data from the Transportation Improvement Program for the Twin Cities Metropolitan Area provided information on the Interstates and Truck Highways in the seven counties of the metropolitan area. The data from Hennepin County Capital Budget provided information on the County State Aided Highways (CSAH) in the Hennepin 
Table 2. Summary of the 1995 highway network of the Twin Cities Metro Area, classified by road type

\begin{tabular}{|c|c|c|c|c|c|c|}
\hline & \multicolumn{2}{|c|}{ Interstates } & \multicolumn{2}{|c|}{ Trunk Highways } & \multicolumn{2}{|c|}{$\begin{array}{l}\text { Hennepin County } \\
\text { Highways (CSAH) }\end{array}$} \\
\hline & $\begin{array}{l}\text { Number } \\
\text { of links }\end{array}$ & $\begin{array}{l}\text { Total link } \\
\text { length }(\mathrm{km})\end{array}$ & $\begin{array}{l}\text { Number } \\
\text { of links }\end{array}$ & $\begin{array}{l}\text { Total link } \\
\text { length }(\mathrm{km})\end{array}$ & $\begin{array}{l}\text { Number } \\
\text { of links }\end{array}$ & $\begin{array}{l}\text { Total link } \\
\text { length }(\mathrm{km})\end{array}$ \\
\hline Total & 1193 & 710 & 2138 & 1808 & 1658 & 1023 \\
\hline
\end{tabular}

Note: Only links used in the analysis indicated.

Table 3. Summary of $\Delta V K T$

\begin{tabular}{|c|c|c|c|c|c|c|c|c|c|}
\hline \multirow[b]{3}{*}{ Year } & \multicolumn{9}{|c|}{ Summary of $\Delta V K T\left(V K T_{t}-V K T_{t-2}\right.$} \\
\hline & \multicolumn{3}{|c|}{ Interstates } & \multicolumn{3}{|c|}{ Trunk highways } & \multicolumn{3}{|c|}{ CSAH } \\
\hline & $<0$ & $=0$ & $>0$ & $<0$ & $=0$ & $>0$ & $<0$ & $=0$ & $>0$ \\
\hline 1998 & 61 & 25 & 1107 & 403 & 298 & 1437 & 677 & 78 & 903 \\
\hline 1996 & 176 & 60 & 957 & 475 & 225 & 1438 & 554 & 127 & 977 \\
\hline 1994 & 198 & 61 & 934 & 587 & 303 & 1248 & 647 & 173 & 838 \\
\hline 1992 & 231 & 42 & 920 & 450 & 303 & 1385 & 888 & 160 & 610 \\
\hline 1990 & 181 & 52 & 960 & 562 & 135 & 1441 & 483 & 142 & 1033 \\
\hline 1988 & 186 & 0 & 1007 & 561 & 75 & 1502 & 655 & 85 & 918 \\
\hline 1986 & 288 & 22 & 883 & 515 & 101 & 1522 & 379 & 82 & 1197 \\
\hline 1984 & 79 & 8 & 1103 & 465 & 60 & 1613 & 464 & 30 & 1164 \\
\hline 1982 & 330 & 4 & 859 & 736 & 46 & 1356 & 709 & 76 & 873 \\
\hline 1980 & 696 & 17 & 480 & 894 & 90 & 1154 & 769 & 77 & 812 \\
\hline Total & 2426 & 291 & 9210 & 5648 & 1636 & 14096 & 6225 & 1030 & 9325 \\
\hline
\end{tabular}

Note: Only links used in the analysis are indicated.

County. The investment data obtained from these two sources provided information on the new links constructed and the expansion to the existing links between 1978 and 1998 .

The data sources had to be merged to get a final network database. First, the network data were merged with the AADT data so that each link on the network had the corresponding AADT associated with it. This was done using a $\mathrm{C}$ programme. The MCD data were merged with the network data using Arcview GIS. The network map and the MCD map in GIS format were obtained from MetroGIS. The MCD map was overlaid on the network map and from this it waas possible to identify the MCD to which each link belongs. The results of this merging gave a final database which contained information about the links and their characteristics, the
AADT on the links, the MCD to which it belongs and the population estimates for the MCD.

Each link in the network was represented as a one-way link. For each link in the network, the corresponding parallel link was identified and the AADT on the parallel link was obtained. ${ }^{1}$ For analysis purposes, the AADT on the link was converted into vehicle kilometres travelled (VKT) by multiplying the AADT on the link by the link length.

For each MCD, the adjacent MCDs were identified from the GIS map. The corresponding population estimates were summed to get the adjacent MCD population. Hence each link in the network was associated with the population of both the MCD to which it belongs and the population of the adjacent MCDs. 


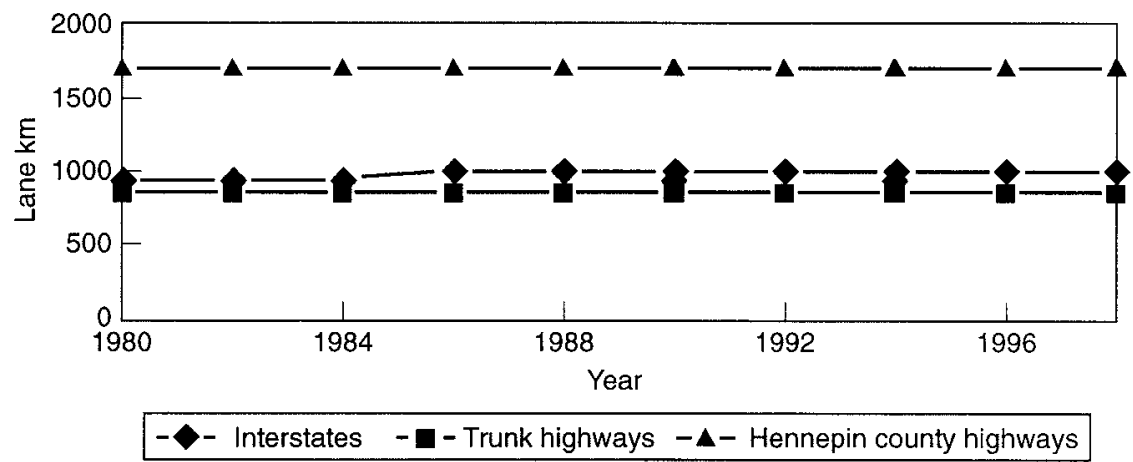

Figure 2. Summary of lane kilometers. Note: Only links used in the analysis are indicated.

The next step was to build (or deconstruct) the network for the various years. The 1995 network was used as the base year network. The investment data provided information on the lane additions in the links for the various years. The network was built forward from 1995 to 1998 and backward from 1995 to 1978. Using this information, lanes were added to or subtracted from the previous year's network to build the network for any particular year. The final built network contained 8281 links for a period of 20 years from 1978 to $1998 .^{2}$

The analysis concentrated on the interstates and trunk highways in the seven counties and the Hennepin County state-aid highways (CSAH) because complete data could be obtained for these road types. The data-set was separated by road type. The traffic flow in terms of VKT was used for the years 1978 to 1998 for each road type. In addition to the network variables, the population estimates of the MCDs and adjacent MCDs were also considered. Since the population estimates were available from 1980 only, the final data-set used was a panel data-set of the network for the years 1980 to 1998.

\section{Model Specification}

The model predicts the change in VKT based on the flow and capacity conditions on the link and the neighbouring links. The analysis focuses on how changes in capacity given by lane additions and expansion would have an effect on the traffic flow in the link. In addition to looking at the influences of the changes on the link on traffic flow, the analysis examines the changes on neighbouring links.

The basic difference model used in this analysis is given below.

$$
\begin{gathered}
\Delta Q=f\left(\Delta Q_{n}, \Delta Q_{p n}, \Delta L_{n}, \Delta L_{p n}, \Delta P_{n}, \Delta P_{a n},\right. \\
\left.Q_{t}, Q_{p t}, L_{t}, L_{p t}, P_{t}, P_{a t}, D\right)
\end{gathered}
$$

where: $t=$ base year; $\Delta Q=$ change in VKT on the link between time $t+n$ and $t$; $\Delta Q_{n}=$ change in VKT on the link between time $t$ and $t-n ; \Delta Q_{p n}=$ change in summed VKT on the parallel links between time $t$ and $t-n ; \Delta L_{n}=$ change in the number of lanes on the link between time $t$ and $t-n$; $\Delta L_{p n}=$ change in the summed number of lanes on the parallel links between time $t$ and $t-n ; \Delta P_{n}=$ change in the population of the MCD to which the link belongs, between time $t$ and $t-n ; \Delta P_{a n}=$ change in the summed population of the adjacent MCDs between time $t$ and $t-n ; Q_{t}=\mathrm{VKT}$ in the link at base year $t, Q_{p t}=$ summed VKT in the parallel links at base year $t ; L_{t}=$ number of lanes in the link at base year $t ; L_{p t}=$ summed number of lanes in the parallel links at base year $t ; P_{t}=$ population of the MCD to which the link belongs, at base year $t ; P_{a t}=$ summed population at the adjacent MCDs, at base year $t ; D=$ dummy variable for the base years; $n=$ lag year $=2,4,6,8$.

The model given above is estimated with a 
linear functional form using ordinary least squares regression. Other functional forms and transforms of the variables were tested with similar results and excluded for brevity (Parthasarathi, 2001).

The dependent variable is the change in VKT of a link $\left(\mathrm{VKT}_{t+n}-\mathrm{VKT}_{t}\right)$. The independent variables are the change variables of the previous years and the base year variables. The change variables refer to the difference in the value of the variable at time $t$ and time $t-\mathrm{n}[(t)-(t-n)]$ while the base year variable refers to the value of the variable existing at time $t$ and $\mathrm{n}$ refers to the lag variable.

The traffic counts obtained from MnDOT are updated only once every two years on many links. Due to this the value of the lag variable $n$ was set at 2 and multiples of 2 namely 4, 6 and 8 . Hence the model has 4 different sub-types: the 2-year lag model, the 4-year lag model, the 6-year lag model and the 8-year lag model. Also, only even years are considered in the analysis. The 4 lag models allow us to account for both the short run and long run effects that are likely to be seen due to changes in the network.

The analysis of each of the road types namely Interstates, Trunk Highways and $\mathrm{CSAH}$ roads in Hennepin County are done separately. Each road type is analysed using the four different sub-types of the difference model given above. In total 12 different trials of the basic difference model are carried outEach sub-type of the difference model is constrained by the data-set available. The independent variables in each version are calculated as $[(t)-(t-n)]$. The constraint for each sub-type of the difference model is that for the independent variables, $t-n$ should be $\geq 1980$, which limited the years that could be considered and consequently the sample size.

Dummy variables have been introduced for each base year. This has been done to see the behaviour of each base year dummy variable rather than using the variable year as a continuos variable in which the effect of the base year dummies cannot be clearly seen.

\section{Selectivity Bias}

When the dependent variable is observed only for a non-random set of observations, there is a possibility of selectivity bias. Levinson and Karamalaputi (2002) observe that expansion of a link depends on a number of factors including travel demand, adjacent and parallel link properties, project costs, budget constraints and demographic characteristics. Since expansion of a link is based on characteristics not captured entirely by the models in this study, we need to check for potential selectivity bias. This self-selection of links that are expanded induces a correlation between change in lanes and the error term of the regression. The estimated coefficients of variables are biased if selectivity bias is present. A chow test is performed to check if the coefficients of variables change significantly in the sub samples of lane expansion and no lane expansion. The test statistic is given by:

$$
\frac{\left[E_{c}-\left(E_{1}+E_{2}\right)\right] / k}{\left(E_{1}+E_{2}\right) /\left(n_{1}+n_{2}-2 * k\right)}
$$

where $E_{c}$ is the error sum of squares in the model with complete observations, $E_{1}$ and $E_{2}$ are the error sum of squares of each of the sub sample models, $k$ is the number of parameters estimated and $n_{1}, n_{2}$ are number of observations in the sub samples. Note that the change in number of lanes is not included in the above models. The test statistic follows a $\mathrm{F}\left(k, n_{1}+n_{2}-2 * k\right)$ distribution. Using this test, it was found that only interstate highways have selectivity bias.

Selectivity bias is corrected by using a two-step estimation procedure. In the first step, a probit model is estimated to calculate the probability of link expansion. Using this probability, the Inverse Mills Ratio (IMR) is calculated for each of the variables (Greene, 1993). The second step is to include the IMR variable in the regression along with other explanatory variables to correct selectivity bias, so the interpretation of the coefficients of the variables is valid for the entire population. Expansion of a link can be modelled as: 


$$
\begin{aligned}
y= & \mathrm{f}\left[C_{i j}, L_{i j}, \Delta\left(Q_{i j}^{*} L_{i j}\right), Q_{i j} / C_{i j}, Q_{p} / C_{p},\right. \\
& E_{i j}, B, Y, X,\left(Q_{h i}+Q_{j k}\right), \\
& \left(C_{h i}+C_{j k}-C_{i j}\right), \Delta\left(Q_{h i}+Q_{j k}\right), \\
& \left.\Delta\left(C_{h i}+C_{j k}\right), P, \Delta P\right]
\end{aligned}
$$

where: $y=$ dummy for link expansion; $C_{i j}=$ capacity on link $i j ; L_{i j}=$ length of link $i j ; Q_{i j}=$ flow on link $i j ; Q_{p}=$ flow on parallel link; $C_{p}=$ capacity of parallel link; $E_{i j}=$ unit expense of construction of improvements on link $i j ; B=$ budget constraint; $Y=$ year of proposed construction-1979; $X=$ distance from the nearest downtown; $Q_{h i}=$ sum of flows on arcs $h i ; Q_{j k}=$ sum of flows on arcs $j k ; C_{h i}=$ sum of capacities on arcs $h i$ (arcs supplying flow); $C_{j k}=$ sum of capacities on $\operatorname{arcs} j k$ (arcs receiving flow); $P=$ population of the surrounding Minor Civil Division (MCD). Note that Flows are bi-directional and $\Delta$ indicates change between time-period $t$ and $(t-n)$.

Levinson and Karamalaputi (2002) estimated the cost of expanding a link using the same data as used for this study. The model is reproduced in the appendix (Table A4). Probit models were estimated separately for interstate highways, trunk highways and Hennepin County Highways. The results are given in Table 4, Table 5 and Table 6 respectively. It was observed that high capacity links are less likely to be expanded while links with high inflow and outflow demand are more likely to be expanded. Links with low cost of expansion are favoured and a higher budget for a year results in the expansion of more links. The coefficient of year is negative and significant in two cases and positive and insignificant for Trunk Highways indicating that the expansion rate of the network decreased. The probabilities estimated by this model are used to calculate the probabilities of link expansion for 2-year, 4-year, 6-year, and 8-year intervals that are in turn used to calculate Inverse Mills Ratio.

\section{Hypothesis}

The specific hypotheses tested in the model are as follows:

-An increase in the number of lanes on the link will increase the VKT on the link, which is the basic induced demand hypothesis.

- An increase in the VKT in past years is expected to have a positive effect on the change in VKT, which reflects the continuing of trends in traffic flow over time.

- The higher the change in the number of lanes on the parallel links, the lower will be the VKT on the link. The parallel links can handle more flow due to the increase

Table 4. Probit model to predict lane expansion on interstate highways

\begin{tabular}{lrrr}
\hline Variable & Coefficient & \multicolumn{1}{c}{$z$} & $\mathrm{P}>|z|$ \\
\hline Capacity of the link & $-7.89 \mathrm{E}-01$ & -8.02 & 0.00 \\
Length of the link & $4.39 \mathrm{E}-01$ & 4.53 & 0.00 \\
Change in VKT over 2 years & $-2.48 \mathrm{E}-06$ & -0.48 & 0.63 \\
Congestion on the link & $-1.28 \mathrm{E}-05$ & -6.28 & 0.00 \\
Congestion on the parallel link & $2.96 \mathrm{E}-06$ & 2.32 & 0.02 \\
Cost of expansion & $-2.64 \mathrm{E}-10$ & -3.5 & 0.00 \\
Budget & $1.29 \mathrm{E}-06$ & 5.84 & 0.00 \\
Year-1979 & $-5.45 \mathrm{E}-02$ & -4.9 & 0.00 \\
Distance from nearest downtown & $-4.20 \mathrm{E}-02$ & -3.74 & 0.00 \\
Flow on adjacent links & $4.45 \mathrm{E}-06$ & 8.92 & 0.00 \\
Capacity of adjacent links & $-2.98 \mathrm{E}-01$ & -9.55 & 0.00 \\
Population & $-2.56 \mathrm{E}-07$ & -0.85 & 0.40 \\
Change in population over 2 years & $-1.62 \mathrm{E}-08$ & -0.02 & 0.98 \\
Constant & $6.54 \mathrm{E}-02$ & 0.28 & 0.78 \\
Number of observations 23 609 & & & \\
Log likelihood -597.41 & & & \\
\hline
\end{tabular}


Table 5. Probit model to predict lane expansion on trunk highways

\begin{tabular}{lrcc}
\hline Variable & Coefficient & \multicolumn{1}{c}{$z$} & $\mathrm{P}>|z|$ \\
\hline Capacity of the link & $-5.34 \mathrm{E}-01$ & -4.99 & 0.00 \\
length of the link & $5.97 \mathrm{E}-01$ & 5.71 & 0.00 \\
Change in VKT over 2 years & $-3.25 \mathrm{E}-06$ & -0.57 & 0.57 \\
Congestion on the link & $-1.38 \mathrm{E}-05$ & -6.48 & 0.00 \\
Congestion on the parallel link & $2.62 \mathrm{E}-06$ & 1.9 & 0.06 \\
Cost of expansion & $-6.91 \mathrm{E}-10$ & -5.45 & 0.00 \\
Budget & $6.83 \mathrm{E}-06$ & 11.6 & 0.00 \\
Year-1979 & $9.56 \mathrm{E}-03$ & 0.71 & 0.48 \\
Distance from nearest downtown & $-6.45 \mathrm{E}-02$ & -4.93 & 0.00 \\
Flow on adjacent links & $4.36 \mathrm{E}-06$ & 8.15 & 0.00 \\
Capacity of adjacent links & $-3.06 \mathrm{E}-01$ & -9.16 & 0.00 \\
Population & $-5.89 \mathrm{E}-07$ & -1.52 & 0.13 \\
Change in population over 2 years & $-9.81 \mathrm{E}-05$ & -2.05 & 0.04 \\
Constant & $-6.14 \mathrm{E}-01$ & -2.34 & 0.02 \\
Number of observations 20 887 & & & \\
Log likelihood -511.55 & & & \\
\hline
\end{tabular}

Table 6. Probit model to predict lane expansion on Hennepin county highways

\begin{tabular}{lrrr}
\hline Variable & Coefficient & \multicolumn{1}{c}{$z$} & $\mathrm{P}>|z|$ \\
\hline Capacity of the link & $-4.849 \mathrm{E}-01$ & -3.32 & 0.00 \\
Length of the link & $2.694 \mathrm{E}-01$ & 3.04 & 0.00 \\
Change in VKT over 2 years & $-2.690 \mathrm{E}-05$ & -2.26 & 0.02 \\
Congestion on the link & $2.700 \mathrm{E}-05$ & 3.31 & 0.00 \\
Congestion on the parallel link & $-3.860 \mathrm{E}-07$ & -0.19 & 0.85 \\
Cost of expansion & $-6.380 \mathrm{E}-10$ & -2.15 & 0.03 \\
Budget & $-1.430 \mathrm{E}-06$ & -2.65 & 0.01 \\
Year-1979 & $-4.407 \mathrm{E}-02$ & -3.72 & 0.00 \\
Distance from nearest downtown & $-1.286 \mathrm{E}-02$ & -1.35 & 0.18 \\
Flow on adjacent links & $1.370 \mathrm{E}-06$ & 1.45 & 0.15 \\
Capacity of adjacent links & $2.997 \mathrm{E}-02$ & 1.16 & 0.25 \\
Population & $-9.450 \mathrm{E}-07$ & -1.92 & 0.06 \\
Change in population over 2 years & $-4.530 \mathrm{E}-05$ & -0.91 & 0.36 \\
Constant & $-1.942 \mathrm{E}+00$ & -6.61 & 0.00 \\
Number of observations $=26550$ & & & \\
Log likelihood $=-449.02$ & & & \\
\hline
\end{tabular}

in capacity and they act as substitutes to the link.

-An increase in the population of the Minor Civil Divisions (MCD) (and adjacent MCDs) to which the link belongs in the previous years causes the traffic flow on the link to increase due to the extra traffic that the rise in population generates. The population variables for the base year, both for the MCDs and adjacent MCDs are expected to have a negative influence on the depen- dent variable, as larger MCDs will have less growth, since they tend to be in mature areas.

\section{Results}

The linear model is estimated separately for each of the 3 road types and 4 lag periods resulting in 12 models in all. All results are attached in Appendix A. The results are summarised in Table 7. The table indicates the 
Table 7. Results (dependent variable $=$ change in VKT between $t+n$ and $t(\Delta Q)$ )

\begin{tabular}{lcrr}
\hline Variable $[(t)-(t-n)]$ & Hypothesis & Summary & Cases \\
\hline Change in lanes on the link $\left(\Delta L_{n}\right)$ & $+\mathrm{S}$ & $+\mathrm{S}$ & $7 / 12$ \\
Number of lanes on the link in base year $t\left(L_{t}\right)$ & & $-\mathrm{S}$ & $5 / 12$ \\
Change in VKT on the link $\left(\Delta Q_{n}\right)$ & $+\mathrm{S}$ & $-\mathrm{S}$ & $9 / 12$ \\
VKT on link in base year $t\left(Q_{t}\right)$ & $-\mathrm{S}$ & $+\mathrm{S}$ & $8 / 12$ \\
Change in lanes on the parallel link $\left(\Delta L_{p n}\right)$ & & $-\mathrm{S}$ & $8 / 12$ \\
Number of lanes on the parallel link in base year $t\left(L_{p t}\right)$ & & $-\mathrm{S}$ & $8 / 12$ \\
Change in VKT on the parallel link $\left(\Delta Q_{p n}\right)$ & $+\mathrm{S}$ & $8 / 12$ \\
VKT on parallel links in base year $t\left(Q_{p t}\right)$ & $+\mathrm{S}$ & $7 / 12$ \\
Change in population of the MCD $\left(\Delta P_{n}\right)$ & $-\mathrm{S}$ & $-\mathrm{S}$ & $7 / 12$ \\
Population of the MCD at base year $t\left(P_{t}\right)$ & $+\mathrm{S}$ & $\mathrm{NS}$ & $7 / 12$ \\
Change in the summed population of the adjacent MCDs $\left(\Delta P_{a n}\right)$ & $-\mathrm{S}$ & $-\mathrm{S}$ & $11 / 12$ \\
Summed population of the adjacent MCDs at base year $t\left(P_{a t}\right)$ & & \\
\hline
\end{tabular}

Key: $-\mathrm{S}=$ negative and significant, $+\mathrm{S}=$ positive and significant, $\mathrm{NS}=$ not significant.

variables considered in the model, the hypothesis formulated for each variable and the summary of the results for each variable. The case column refers to the number of models (out of 12) in which the coefficient of the variables is consistent with that of the summary column.

The results indicate the behaviour of the explanatory variables for all road types considered separately and for all lag models. Some of the variables have shown a variation in their behaviour with respect to the road type indicating that the road type has an influence on the variable. The selectivity bias seen was corrected using the inverse mills ratio from a probit model predicting link expansion.

Considering the lane variable, it is seen at an overall level that the change in the number of lanes on a link in the previous years has a clear positive and significant effect on the change in VKT in 7 of the 12 models. This indicates that as the number of lanes in the link in the previous years increases, the VKT on the link can be expected to increase, which confirms the induced demand hypothesis.

The coefficients of the base year lanes are negative and significant in 5 of the 12 models.

The change in VKT on the link in the previous years has a clear negative and significant effect in 9 of the 12 models, which in general contradicts our hypothesis. The results indicate that we may be seeing an equilibration process as travelers reroute over time to find the shortest time path in a changing environment.

The base year VKT of the link influences the VKT in a positive and significant manner in 8 of the 12 models. The results in general indicate a positive influence on the VKT and are in line with what was hypothesised.

The coefficient for the change in the number of lanes on the parallel links is positive and significant in 7 of the 12 models. An increase in the number of lanes on the parallel links seems to cause the VKT on the link to rise thus contradicting our hypothesis. A possible explanation is that the increase in lanes on parallel routes is a response to rising overall traffic levels, and thus is correlated with growing traffic levels.

The results for the base year lanes on parallel links indicate a clear negative and significant influence on the VKT on the link in 8 of the 12 models. The higher the number of lanes on the parallel links, the lower will be the VKT on the link in future years, which is in line with the hypothesis.

The coefficient for the change in VKT on the parallel links is negative and significant in 8 of the 12 models. This indicates that the change in VKT on the parallel links in the previous years has an overall negative effect on the VKT on the link in future years. The 
base year VKT on the parallel links has a clear positive and significant influence on the VKT on the link in 8 of the 12 models. This indicates that as the base year VKT on the parallel links increases, the VKT on the links in future can also be expected to increase.

The change in population of the surrounding Minor Civil Division (MCD) has a positive and significant effect on the VKT in 7 of the 12 models. Overall, an increase in the population of the MCD to which the link belongs causes the VKT on the link in future years to increase, which is what was hypothesised. The coefficients for the base year population of the MCD to which the link belongs are negative and significant in 7 of the 12 models. The results are consistent with the hypothesis and indicate that larger stable jurisdictions do not produce a change in VKT, while growing MCDs do.

The change in the population of the adjacent MCDs is insignificant in 7 of the 12 models. Thus, in general, the change in population of the adjacent MCDs doesn't seem to have an influence on the VKT on the link in future years. The coefficients of the base year adjacent MCDs shows a very clear negative and significant effect on the VKT on the link in 11 of the 12 models, which contradicts our hypothesis.

Another point is that the base year dummy variables considered are in most cases highly significant and negative indicating that the change in VKT on the link has decreased over the years. Thus as the road system becomes more mature, changes become less significant. It may also indicate a general slowing in traffic growth, as the major changes of the past several decades (female labour force participation rates, auto ownership) have worked themselves through the system.

The results indicate that the VKT on a link in future years is affected by the flow and capacity conditions existing on the link in the previous years. The influence of the conditions existing on the neighbouring links doesn't seem to be very clear from the results.

\section{Elasticities}

The elasticity estimates for the change in lanes on the link in the previous years obtained from the model are summarised in Table 8 . The elasticity estimates indicate the effect a 1 per cent per cent change in the number of lanes on the link in the previous years would have on the VKT on the link in future.

Overall these results are consistent with the summary results shown in Table 1, though somewhat lower. The difference between modelling link expansions and new construction may explain some of the difference. It does not indicate that all new capacity is used up. Thus there are likely to be real travel timesavings due to link expansion after accounting for induced demand. The results do indicate that the capacity is used up more in the long term than the short term, so a short-term measurement of induced demand will underestimate long term effects. Still, in general the elasticities are below 0.6, so that the capacity increases are not simply overwhelmed by new traffic, and the induced demand phenomenon is not insatiable.

Table 8. Elasticity estimates: percentage change VKT/percentage change lanes on the link

\begin{tabular}{lccc}
\hline Model & Interstates & Trunk highways & $\begin{array}{c}\text { Hennepin county } \\
\text { highways (CSAH) }\end{array}$ \\
\hline 2-year lag model & -0.042 & -0.003 & 0.014 \\
4-year lag model & -0.137 & 0.011 & 0.034 \\
6-year lag model & 0.208 & 0.005 & Not significant \\
8-year lag model & 0.552 & Not significant & 0.067 \\
\hline
\end{tabular}




\section{Conclusions}

The focus of this study was to analyse the induced demand hypothesis at a disaggregate level and also identify the influence of network interactions and dynamics. Studies on the induced demand hypothesis to date have mostly been aggregate level studies.

The reason that the link level approach was chosen is that the effects on changes in the network were expected to be clearly seen at the link level. Any capacity changes on a link in the network are likely to have a very clear effect not only on the link alone but also on the other links. The output of a link, measured in terms of VKT here, is going to be affected not only by the capacity changes occurring on it but also by the capacity changes on the neighbouring parallel links. The analysis aimed to understand and measure this neighbouring influence in inducing traffic on a link.

The results indicate that the induced demand hypothesis is largely, but not universally corroborated. The results obtained indicate that the neighbouring parallel links do affect the output of a link. The population estimates also tend to affect the output. Though key conclusions have been drawn for some of the variables like the changes in capacity and flow, the signs and the coefficients obtained for the many of the other variables don't seem to follow any particular pattern.

This analysis is limited to examining expansion on exiting links. That is only those links that already existed and underwent lane additions from the period from 1978-1998 are considered. The induced demand effect is more obvious for other links that were newly added to the network.

A key conclusion that has however emerged from this study is that the capacity expansions on a link in the previous years do have a positive effect on future Vehicle Kilometres Travelled (VKT), which is in line with the induced demand hypothesis. The elasticity calculations show that a 1 per cent increase in the number of lanes on the link in the previous years causes a $0.01-0.6$ per cent increase in the VKT on the link in future years.

Many have argued that the conventional four-step Urban Transport Modelling System is not an accurate description of trip making (Levinson and Kumar, 1994b). In particular, the representation of network flow would not be accurate if demand elasticity is not considered in the theoretical framework.

Levinson and Kumar (1994a) also noted that over the long term, commute times to work tend to be stable. This has been corroborated over a period with significant population growth and lifestyle changes that increased travel demand far in excess of road capacity increases. The induced demand argument must be placed in the larger context of travel and activity patterns. As capacity is added, it may be used up. But that does not mean benefits were not gained. People using the new capacity are now able to pursue opportunities that were too expensive in terms of time budgets previously, and thus are better off, even if only examining the congestion record would not indicate so.

\section{Notes}

1. For each link in the network, the parallel links were obtained and the results were checked with the network map. Parallel links are those that are not connected to the link in question. These links bear the maximum traffic when the link in question was to be eliminated (for details, see Levinson and Karamalaputi, 2002).

2. There were a number of erroneous links. Many links in the network had no traffic count although the link existed. Also, many links had traffic fows on them even though the link did not exist in the regional planning network. Such links were removed from the data-set and were not considered for analysis. A summary of the erroneous links in the network is given in Table A5. The final network used for analysis consisted of 4989 links belonging to the following road types: interstates, trunk highways and county state aid highways (CSAH) in Hennepin County.

\section{References}

Baltagi, B. H (1999) Econometrics, 2nd edn. New York: Springer Verlag. 
BARNES, G. and DAvis, G. (2001) Land use and travel choices in the twin cities, 1958-1990. Report No. 6 of the Transportation and Regional Growth Study, Center for Transportation Studies, University of Minnesota.

Dowling, R. G. and Colman, S. B. (1995) Effects of increased highway capacity: results of household travel behavior survey, Transportation Research Record, 1493, pp. 43-149.

Downs, A. (1992) Stuck in Traffic. Washington, DC: Brookings Institution.

Fulton, L. M., Noland, R. B., Meszler, D. J. and Thomas, J. V. (2000) A statistical analysis of the induced travel effects in the U. S. MidAtlantic region, Journal of Transportation and Statistics, 3(1), pp. 1-14.

GreENe, W. H. (1993) Econometric Analysis, 2nd edn. New York: Macmillan Publishing Company.

Hansen, M. (1995) Do new highways generate traffic, Access, 7(fall), pp. 16-22.

HANSEN, M. and Huang, Y. (1997) Road supply and traffic in California urban areas, Transportation Research A, 31(3), pp. 205-218.

HennePin County, Minnesota (1980-2000) Hennepin County capital budget. Hennepin County.

Kiefer, M. and Mehndiratta, S. R. (1998) If we build it, will they really keep coming? A critical analysis of the induced demand hypothesis. Annual Meeting Preprint Paper No. 980937, Transportation Research Board.

Levinson, D. M and KanchI, S. (2000) Road capacity and the allocation of time, Journal of Transportation and Statistics (in press).

LeVinson, D. M. and Karamalaputi, R. (2002) Predicting network expansion. Preprint CDROM, Transportation Research Board Conference, Washington, DC, January.

Levinson, D. M. and Kumar, A. (1994a) The rational locator: why travel times have remained stable, Journal of the American Planning Association, 60(3), pp. 319-332.

LEVINSON, D. and KUMAR, A. (1994b) Integrating feedback into the transportation planning model, Transportation Research Record, 1413, pp. 70-77.

METROGIS DATAFINDER (http://www.datafinder. org).

Metropolitan Council (http://www.metrocouncil. org).

Metropolitan Council (1978-2000) Transportation improvement program for the twin cities metropolitan area. St Pail, MN: metropolitan council.

Minnesota State Demographic Center (http:// www.mnplan.state.mn.us/demography)

Mokhtarian, P. L., Samaniengo, F. J., Shumway, R. H. and Willits, N. H. (2002) Revisiting the notion of induced traffic through a matched-pairs study, Transportation, 29, 193-220.

Noland, R. B. (1999) Relationships between highway capacity and induced vehicle travel. Preprint CD-ROM, Transportation Research Board 78th Annual Meeting, Washington, DC, January.

OfFice of Transportation Data AND ANALysis, Transportation Data Section, Minnesota DEPARTMENT OF TRANSPORTATION (http://www. dot. state. mn. us/tda/products2. html).

PARThasarathi, P. K. (2001) A disaggregate analysis of induced demand. University of Minnesota.

Pfleiderer, R. H. H. and Dieterich, M. (1995) New roads generate new traffic, World Transport Policy and Practice, 1(1), pp. 29-31.

PindYCK, R. S. and Rubinfeld, D. L. (1998) Economic Models and Economic Forecasts, 4th edn. New York: Irwin McGraw-Hill.

Strathman, J. G., Dueker, K. J., Sanchez, T. ET AL. (2000) Analysis of induced travel in the 1995 NPTS. Center for Urban Studies, Portland State University.

US Census Bureau (2002) Decennial Management Division Glossary (http://www.census. gov/dmd/www/glossary.html\#M).

WhistLer, D. (2000) An online guide to SHAZAM (http://shazam.econ.ubc.ca/intro/index. html). 


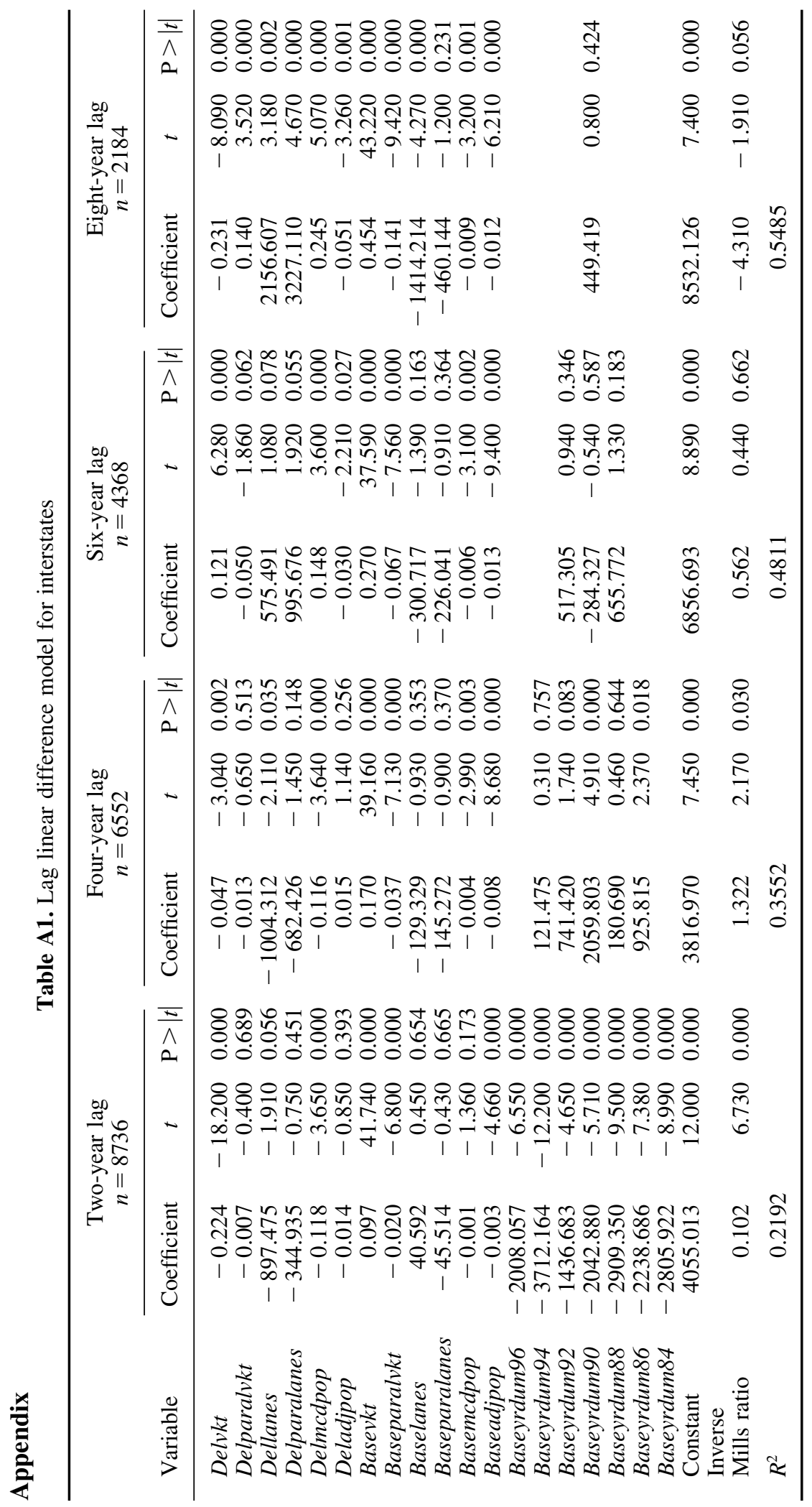




\begin{tabular}{|c|c|c|c|c|c|}
\hline \multirow{3}{*}{ 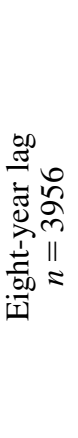 } & $\frac{\hbar}{\hat{\omega}}$ & 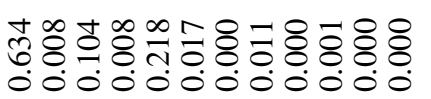 & ơ & \multicolumn{2}{|l|}{ 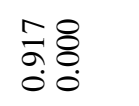 } \\
\hline & - & 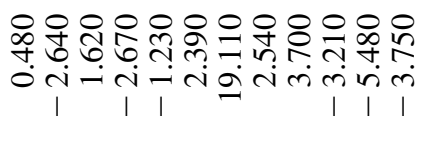 & $\stackrel{8}{\infty}$ & $\begin{array}{l}8 \underset{0}{0} \underset{0}{0} \\
\dot{0} \underset{+}{+}\end{array}$ & \\
\hline & 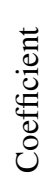 & 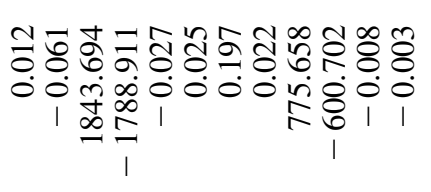 & $\underset{\substack{f \\
\stackrel{\infty}{f}}}{\stackrel{m}{\sim}}$ & 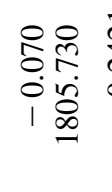 & 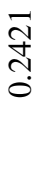 \\
\hline & $\overline{\bar{\hbar}}$ & 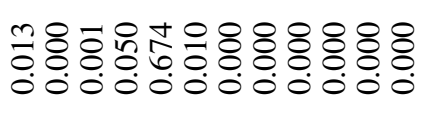 & 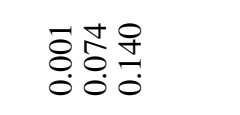 & $\begin{array}{l}\text { No } \\
\text { 요 } \\
00\end{array}$ & \\
\hline 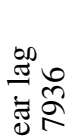 & 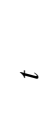 & 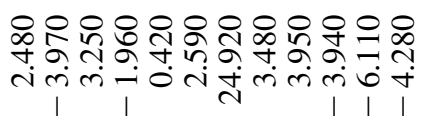 & 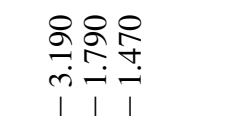 & $\begin{array}{l}\text { 죠 } \\
\text { ஸి } \\
1\end{array}$ & \\
\hline$\ddot{x}=$ & 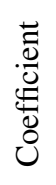 & 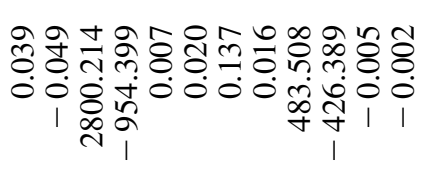 & 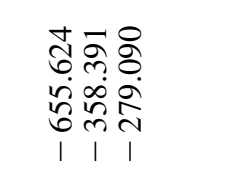 & 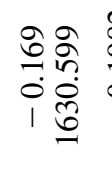 & $\begin{array}{l}\stackrel{1}{\infty} \\
\stackrel{\infty}{\circ} \\
\stackrel{0}{0}\end{array}$ \\
\hline & $\frac{\bar{N}}{\hat{a}}$ & 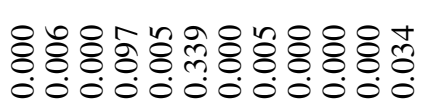 & 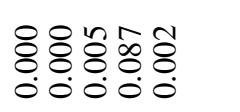 & 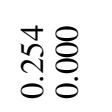 & \\
\hline 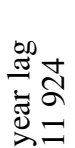 & + & 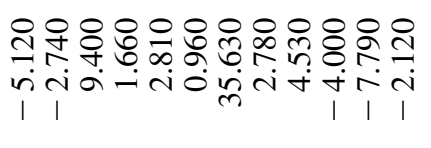 & 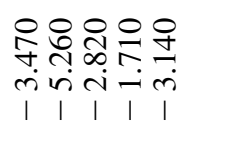 & $\begin{array}{l}\text { 요 } \\
\text { İ } \\
\text { I }\end{array}$ & \\
\hline 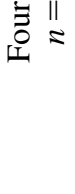 & 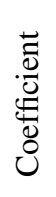 & 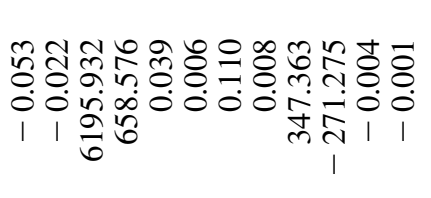 & 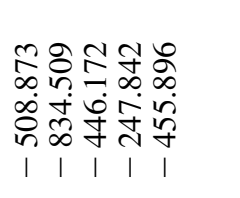 & 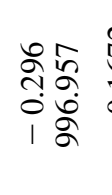 & $\begin{array}{l}\frac{1}{6} \\
\frac{1}{0}\end{array}$ \\
\hline & $\overline{\bar{N}}$ & 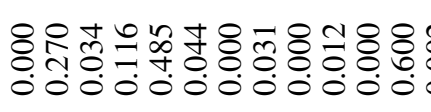 & 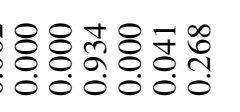 & $\begin{array}{l}9 \\
\infty \\
\infty \\
0 \\
0\end{array}$ & \\
\hline 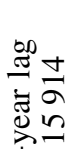 & - & 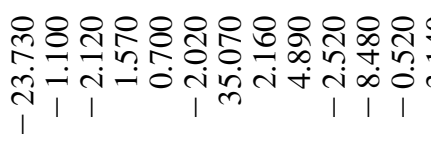 & 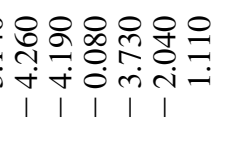 & 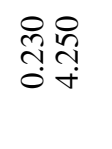 & \\
\hline$B^{0}=$ & 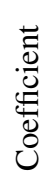 & 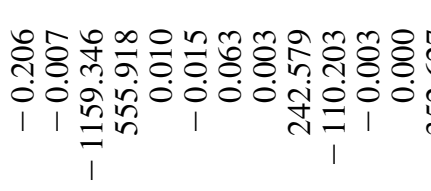 & 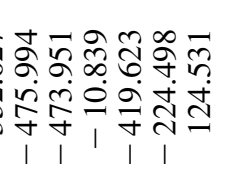 & 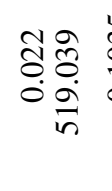 & 管 \\
\hline & $\frac{0}{\frac{\pi}{\pi}}$ & 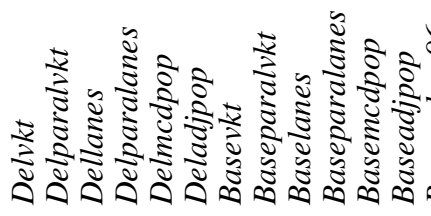 & 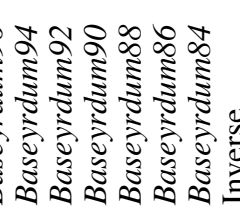 & 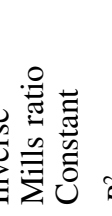 & \\
\hline
\end{tabular}




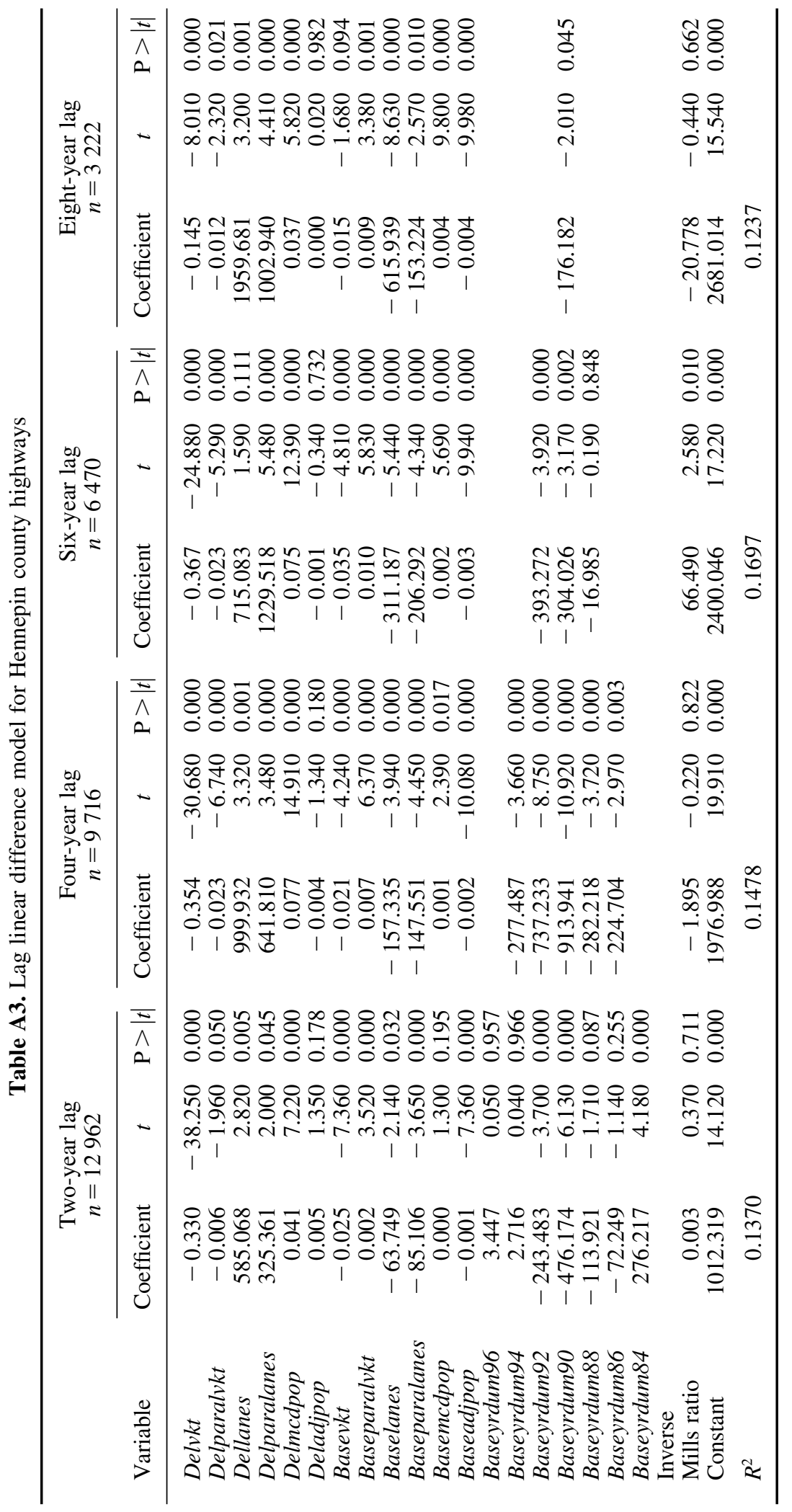


Table A4. Cost model to estimate cost of link expansion

\begin{tabular}{lcrl}
\hline Description of the Variable & Coefficient & $t$ & $\mathrm{P}>|t|$ \\
\hline Lane-km of construction & 0.28 & 4.1 & $0.00^{* * *}$ \\
Dummy for new constructions & 0.40 & 2.2 & $0.03^{* *}$ \\
Dummy for interstate roads & 1.43 & 4.9 & $0.00^{* *}$ \\
Dummy for state roads & 0.52 & 2.3 & $0.03^{* *}$ \\
Log of year-1979 & 0.76 & 7.1 & $0.00^{* * *}$ \\
Log of duration of construction & 0.36 & 2.7 & $0.01^{* *}$ \\
Distance from nearest downtown & -0.03 & -2.1 & $0.04^{* *}$ \\
Constant & 5.45 & 18.5 & $0.00^{* *}$ \\
Number of observations 102 & & & \\
Adjusted $R^{2}$ 0.65 & & & \\
\hline **indicates significant at the 5 per cent level. & & \\
Source of model: Levinson and Karamalaputi (2002). &
\end{tabular}

Table A5. Erroneous links in the network, which were removed

\begin{tabular}{lc}
\hline & Number of links \\
\hline Links in built network initially & 8281 \\
Remove CSAH links in all other counties except Hennepin County & 2592 \\
Remove links with lanes $>0$ but $a a d t=0$ & 630 \\
Remove links with lanes $=0$ and $a a d t>0$ & 70 \\
New total & 4989 \\
\hline
\end{tabular}




\section{Author Query Sheet}

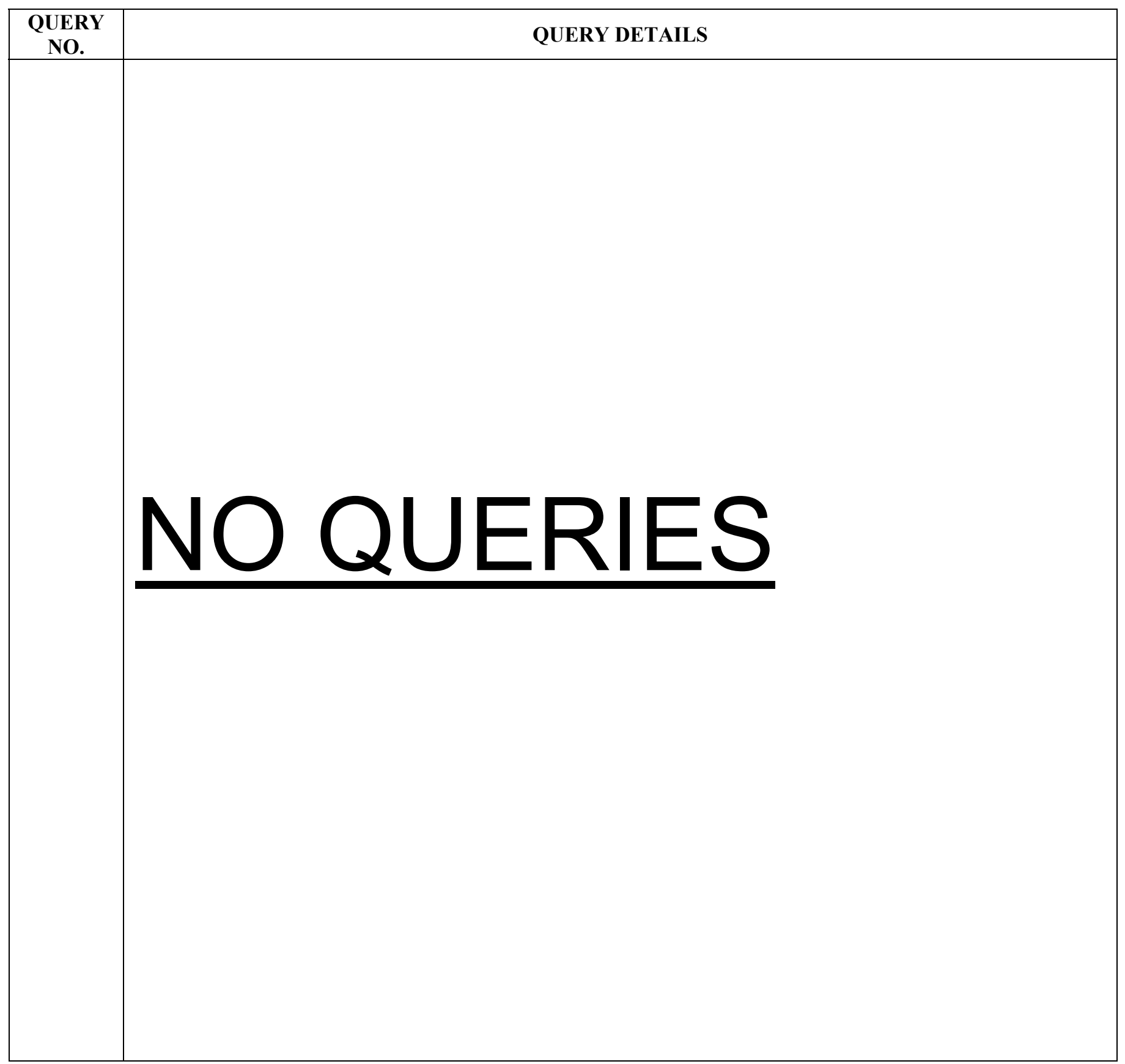

